tics are necessarily unreliable as to the ultimate permanency of the cure of these cases. The best statistics are those shown by the Swedish Hospital, where out of 300 cases a large percentage of recoveries is shown, and if statistics are worth anything in determining $A$ he success of a method, we must place some reliance on these. It wonld be well to have patients come back every year for the purpose of $: 2$. examination.

I)r. Fenger, if I correctly understood him, speaks of the influence of suppuration in curing these wounds by letting them heal from the bottom, but in the various subcutancous operations that is exactly what it is intended to avoid. There is no (loubt that sup). puration will make a radical cure of hernia if the patient's strength lasts, and the suppuration does not extend into the abdominal fascia. That was the method by which the old red-hot irons accomplished their purpose. The nineral acids produced a radical cure by the destruction of the tissue and healing from the bottom. The seton also performed a cure, but it has so many disadvantages that it is not to be compared with those procedures that stop the inflam. matory processes short of the decomposition or death of the exudate. In regard to operating on children, I think the argument cannot be regarded as sound that we should not operate on them on account of the difficulty of keeping a bandage on, for surely if any cases are to be benefited by an operation for radical cure, they are those in which the patient is young enough to grow-in which the tissues can be brought together and retained with great hope of a permanent cure. Everybody knows that cases do recover by the use of the truss, but the proportion, I believe, is less than by any other method. As stated by Professor Gunn, it is found that a majority of operations for strangulated hernia are, in effect, really operations for the radical cure, and there are more than five cures from operations to one after ap. plication of the truss. And when we remember that there are 250,000 trusses manufactured per annum in Philadelphia alone, I doubt very much if it can be shown that trusses have even a fair percentage of recoveries following their use.

DR. WM. 'T. BEI,FIEID reported a case of

SUPRA.PUIHC CYSTOTOMY WITH IEXTRACTION OF IAARGW CAICUI, AND CORROSIVE SUBI.IMATE POISONIN(;.

The patient was a feeble, emaciated man, $7 \mathrm{I}$ years old, who for nine years had suffered from cystitis of steadily increasing severity, caused, as was supposed by his v:urious physicians, by prostatic enlargement. He had been sounded for stone a year ago under chloroform, but with negative result. For two years he had been unable to empty the bladder except by catheter. He refused permission to introduce the sound because convinced that he had no stone, but was anxious to have an operation for the removal of the prostatic enlargement.

June 7 , supra-pubic cystotomy was undertaken for the purpose of removing by galvano cautery that portion of the prostate which was assumed to project into the bladder. The introduction of the sound under ether revealed a large stone; the usual incision was made; the finger in the bladder found two calculi, one behind the prostate, the other adhering to the fundus of the bladder, each about as large as a walnut. The first stone was crushed and the second with much difficulty removed entire. The patient was so collapsed that no attempt was made to remove the prostatic outgrowth, which could have been accomplished without much difficulty, and the following day the temperature was $100.5^{\circ}$, the highest observed. On the third day it was normal and so remained. 'Ihe wound was irrigated once daily with a bichloride of mercury solution. The progress was entirely favorable until the eleventh day, when there began a severe diarrhora with much rectal pain and tenesmus, and later the evacuations were tinged with blood and the patient complained of a metallic taste. Sublimate poisoning was recognized and the solution discontinued. Temporary improvement followed, but death ultimately resulted on the thirty-sixth day after operation. No autopsy was permitted, but a hasty examination of the abdominal contents was made. Peritoneum, kidneys and bladder were normal, except that the latter was much hypertrophied. The intestines could not be opened; the calculi weighed 2 ounces and 6 drachms.

THE DEATH OF DR. F. H. HAMHTON.

Dr. Truman W. Muliek offered the following resolution, which was adopted:

WHEREAs, 'This Society has learned with deep regret of the death of Dr. Frank Hastings Hamilton, of New York, and

Whereas, In his death the United States has lost one of its most distinguished surgeons; one of its ablest teachers; one of the purest patriots, and, in his private life, one of the most amiable of men; therefore, be it

Resolved by this Society, that we hereby give public testimonial to the many virtues of the deceased, and that we tender his family the assurance of the profound sympathy of this Society with them in the hour of their affliction. And that a copy of these resolutions be furnished them, and a copy spread upon the records.

\section{SUFFOLK DISTRICT MEDICAL SOCIETY.}

\section{Section for Cimicai. Medicine, Pathology AN1) HYGifne.}

Stated Mceting, May I 2, I\&\&6.

Dr. F. I. Kengit, Chairman.

Aibert N. Brongel', M.D., Slicretary.

Previous to the papers of the evening, the Chairman announced that D)r. Bowditch desired to address the Section.

DR. BOWDITCH said that he had three articles which he would present to the Section, two of which would be hereafter placed in the portfolio of the Boston Medical library. They all held important relations with the history of medicine, and he thought they would be interesting to the members.

First. A splendid lithograph of Vesalius, "The 
Father of Modern Anatomy." No one could look at it without feeling that if Vesalius had not been great in our profession, he would have been great in any walk of life. One could believe from his fine commanding brow and calm look that he might have been a statesman. He was born in Brussels in $15 \mathrm{r} 4$, and died in 1564 of starvation in the Island of Zante, where he had been shipwrecked on his return from a pilgrimage to the Holy J and. Accused by the minions of the Incuisition of having begun to dissect a man while the heart was still palpitating, he was saved from death only by the favor of Philip. II, to whom he was chief surgeon. He had taught anatomy at Pavia, Bologna and Pisa from 1540 to 1544 , and had large crowds of students to hear him. His immortal work, "IDe Corporis Humana Fabrica," in seven volumes, was first printed at Basle in 1543. Boerhave and Albinus published another edition in folio in 1725 at lieyclen.

Second. A pharmacopoia published at Cologne with Petrus Holzeming as editor, a worthy man doubtless, but now wholly unknown to fame, so far as biographical dictionaries are able to tell us. It is a thin folio volume, with large, well engraved titlepage. At the top are the armorial bearings of Cologne. Below is a view of the city. On the side, are four physicians, namely: St. Iuke, St. Parataban, St. Agmar, and St. Damianas. The last three suffered martyrdom in the fourth century. St. Connes was for many years the patron saint of physicians. A church dedicated to his memory in the thirteenth century was taken down in 1832 . At one time the fraternity of priests of St. Connes taught medicine there. Ambroise Pare in the sixteenth century gained his title of Master Surgeon from that Faculty. The pharmacopceia is a most interesting work, as illustrative of the absurd lengths our fathers in medicine went in the number of articles put in their prescriptions. Generally speaking there were one or two active ingredients, as aloes, opium, hyoscyamus, etc., in a prescription, and the remainder were inert. The most remarkable in the book is an electuary powder. It contains fifty four ingredients and was styled "Pulvis Subtilissimus." In this prescription, human nature had evidently gone to the utmost extreme of overmedication. The whole book with its absurd remedies seems to prophesy homoopathy, with its single and equally absurd infinitesimals. Man never goes toward the truth in a straight line, but in a pendulum course.

Third. A photograph of a painting by Watteall, caricaturing in pencil after Moliere had done so with his pen, the absurdities of the faculty and the extremes to which the public were led by eulogiums on the tuse of the "clystere." Moliere wrote his "Malade Imaginaire" for the opera of the king and noblesse. Watteau, coming after him a few years, painted the scenery on the same stage. The painting which the photograph represents is in the museum at I.ille, in France. It shows an immense army of people coming to meet the great Doctor, who is dressed in fur-bordered robe, with feathers in his hat. $\mathrm{He}$

1 Duke Don Nicholas, so called because prepared by an abbot for the son of I on Nicholas. stands erect with immense gravity and an important look, his right arm extended as if giving decided directions in regard to a patient who is about to have an enema given to him. An immense crowd looking like an army covers the background, each person armed with a huge syringe, instead of the usual trappings of war. Upon the top of the staff; bearing the color of the regiment, instead of the imperial eagle appears an upturned chamber utensil which shall be nameless. Various groups are seen in the foreground, of a most realistic character. $\Lambda$ lady with glutei and legs exposed, and two negroes administering an enema. A lady with her lapdog on her arm and her husband are apparently leaving the scene, but are followed by an attendant of the doctor, armed with a syringe, who is evidently entreating her to allow him to give her an enema. On the other side of the picture is a burly postman, set upon by two attendants, one of whom has pulled the hat over the eyes of the struggling victim, while the other is preparing to give him the injection, which one sees the postman will not readily submit to. But most comical of all is a poor, evidently costive dog, with curved back, plainly striving in vain for a dejection, and mutely appealing for an enema for his relief. One has only to read the "Malade Imaginaire" of Moliere, to get a full explanation of this gross caricature. At the same time it shows the absurd length to which our fathers went in regard to the rectum, as according to the pharmacoporia above described, they had a half century or more before, filled the mouths of their patients with their subtle powders. Who can wonder at homoopathy and eclecticism in consequence of such nonsense.

Dr. GRACE, WOI,COTT read a paper on

\section{A CASE OF UICERATIVE ENIOCARDITIS.}

(See p. 264.)

Dr. F. C. SHATTUCK, upon being invited to open the discussion, expressed his interest in the well reported case which had just been read. The pathology of endocarditis in general presents problems at once interesting and difficult, to the solution of which we thought ourselves nearer some years ago than we do to-day. Until lately the real distinction between ulcerative and simple endocarditis was thought to lie in the presence in the former of micrococci, and the term diphtheritic endocarditis was proposed to char. acterize the process at one time. To these organisms the infectious nature of the affection was attributed; to them it was thought to be due that emboli excited suppurative inflammation about their points of lodgment. This distinction now fails us since Klebs, Köster and others find micrococci in the products of any and every endocarditis, without having succeeded as yet in distinguishing between those accompanying forms which are clinically so different. Anatomically the difference is rather one of degree than of kind, and hence Osler prefers the term malignant to the term ulcerative. In an endocarditis of malignant course there may be no more ulceration than in a benign case of warty endocarditis; and, on the other hand, there may be well-marked ulceration from very different causes. The main anatomical distinction is 
in the different results of embolism; as to the patho. logical distinction we are at present ignorant; the clinical distinction is more clearly marked. Thus we are led to the eminently practical question of diagnosis. In some malignant cases the diagnosis may be marle with tolerable certainty. We know that the process is especially liable to attack valves which are the seat of changes dependent on previous disease, notably sclerosed valves; and hence grave typhoid or py:emic symptoms, for which no other cause can be assigned, in an individual known to be the subject of old valvular disease are, to say the least, suggestive. Similar symptoms with indications of embolic abscesses in a case of acute rheumatic endocarditis are, in like manner, suspicious; but this association is, according to Osler, rare. In cases of primary malignant endocarditis the diagnosis may be reached by a happy guess, but is generally beyond our powers. The general symptoms vary very widely in different cases, simulating typhoid fever, pyamia, malaria, or some other general infectious disease; the leading symptoms may be cerebro-spinal; symptoms pointing to the heart may be wanting or excessively obscure. If the heart was previously healthy the organ is not enlarged and the course of the disease is usually too short to allow it to become so; while a souffle can easily be attributed to so.called dynamic causes. A case which recently occurred at the Massachusetts General Hospital, in the service of Dr. Abbot, the antopsy on which the speaker attended, well illustrates the impossibility of diagnosis at times. A woman died afrer an illness of ten days or so, with ill-defined but rather typhoidal symptoms and no indication of cardiac disease. Primary ulcerative or malignant endocarditis limited to the tricuspid valve with emboli in the lungs was found. The speaker had seen two or three cases in life in which he had suspected this form of disease, but had not been so fortunate as to secure an autopsy to overturn or confirm the cliagnosis. He congratulated Dr. Blodgett both on the diagnosis in the case just reported and on its verification.

I)R. li. (i. CuTter expressed much interest in the case reported He had never seen an instance of ulcerative endocartis at antopsy, but had had, a few years agc, a patient under his care with the following history; a child of 6 had passed through an attack of mumps, under another physician; two other children were sick with the disease about the same time. Some days afterwards the child, having been all the time ailing, was seized with chills, fever, pain in the precordia, and restlessness. There was found to be a loud systolic nurmur at the apex. 'The patient got worse, the circulation in one of the arms suddenly ceased, accompanied by pain and swelling. The femoral artery in one of the legs became plugged soon after, associated with severe pain. 'The murmur ceased beiore death, which occurred about a week after the patient was first examined.

1)R. H. I. BowDrrcu stated that he had never seen a case of this discase in his life, and that the condition was unknown to him. The sprecimen was a most interesting one, and showed a new source of danger in diseases of the cardiac tissues. Dr. Bowditch asked if the diagnosis of ulcerative endocarditis were made before death, and if so, on what grounds was this opinion based?

DR. Brongetr replied that he had the privilege of examining the patient before death, and from the his. tory of a long-continued organic disease of the heart which had been studied by careful physicians for many months, to which a new and must serious complication had been suddenly added, he was led to review the conditions to which this unexpected change might be ciue. The character of the symptoms observed at this time was essentially that of acute septicamia; that is, there was acute pain in various parts of the body which were not before the seat of disease. The pulse and temperature were very high, the patient was in a condition of stupor, almost amounting to apathy, and resembled the state called "typhoid" in many asthenic diseases. The array of symptoms thus calling attention to a condition so closely approximating to that of surgical pyiemia, it seems only a short way to the diagnosis which alone would sufficiently explain the symptoms. The autopsy was of necessity very hastily made, and gave no time to examine the other visceral organs, which might possibly have shown other interesting pathological conditions connected with the state of the heart.

DR. SHATtuck said that in any case of enslocarditis we maly have embolic formations in the bloodvessels. In benign endocarditis the emboli do not occasion suppuration, while in the form of endocarditis which we may for the sake of comparison call "malignant," the emboli are followed by suppuration, and the appearance of a train of clinical phenomena bearing considerable resemblance to septicamia.

Dr. BENNETT F. JAVEnport spoke of the

PHYSICAL, ANI) CHEMICAI, QUAIJTLS OF ORIMNARY Cows' MII.K,

and added: The question of the age of the milk which is given to our city children I consider as of very much greater importance than it is usually deemed by physiciats. There is no fluid that I know of which is a more rapid absorbent of foul odors of all kinds, or which offers a more fertile field for bacterial growths. Yet most of the milk, even when just delivered to the consumers in this city, is already in its third day of age, and has been exposed to a probability of contamination so great that I very much wonder that it does not become downright soured before the time of the next daily delivery. Very much of it is but little short of this stage. I am firmly persuaded that it is to this changed condition in the milk, to which city folks have become so accustomed as to consider it the proper and natural condition, that a very large proportion of the summer diarrhoea and the resulting mortality among the children in our cities is due. If any one wants ocular proof of the grosser forms of contamination to which city milk is exposed, he has but to visit any of the larger milk depots of the city, and to look at the nature and the quantity of the foreign material left upon the cloth strainers comnected with the centifical machines used for separating the crean from the surplus milk of the day. If he does not then learn by seeing with his own eyes what he could otherwise hardly be brought to believe to be 
possible, I am very much mistaken as to what are the real facts. Very fortunate indeed would it be, if only the firm and already dissolved impurities could also be thus readily separated out from the milk.

We, as physicians, have learned to know that milk about upon the point of changing will more disturb the digestion of a child than that which has already turned sour. I believe that the difference in the coagulation of breast and cow's milk in a child's stomach is more owing to the difference in the chemical reaction of these two milks, and in the amount of albuminoids contained therein, rather than to any difference in the nature of these albuminoids, for cow's milk, even when fresh, is of an acid reaction, while breast milk is neutral, or may be slightly alkaline. Then, too, cow's milk contains a much larger amount of albuminoids. Making cow's milk of a neutral or slightly alkaline reaction will render this curd finer and softer, and this is also accomplished by diluting with fluids or with soft solids, for which barley flour or malted extract serves well.

When it is desired to add cream to the diluted and sweetened milk when prepared for a child, I think it is better here in the city to use sweet cream raised by the centrifical machine, rather than that obtained by separation from standing, which necessitates it being just so much the older, when one of the chief troubles is that it is already too old. Such sweet cream is to be had of the large milk depots in the city.

I think that if physicians would instruct all their patients to demand that milk be delivered to them the same day that it is brought into the city from the country, this would become the more common custom of the trade, and that there would be a marked decrease in the infant mortality during the summer months, for if we cannot secure proper cleanliness in the care of the milk, we might at least thus shorten materially the time during which fermentative contaminations would have a chance to work out their harmful changes.

1)R. GRORCE W. Gaivin exlibited an

$$
\text { IMPROVED INHALIR, }
$$

which he described as follows: The inhaler is the invention of Dr. Geo. A. Evans, of Brooklyn, New York, and a full description of it, with a group of cases treated by him, was pulblished in the Ner' York Medical Journal, March 6, 1886 . The great obstacle to overcome in the local treatment of pulmonary diseases, is the condensation of the vaporized medicament in the mouth, pharynx, and upper air passages. This has been overcome by 13r. Evans's instrument, which can reduce any fluid medicine or solution to so fine a degree that it can pass the bronchial tubes without condensing and reach the air cell of the lungs in which is stored the residual air. The changes in the lungs in pu-monary phthisis bring consolidation, tissue necrosis, putrefaction, decomposition, and septic absorption (I am not now considering tubercle, its nature, etc., but what is considered pulmonary consumption); it is natural to suppose that if we can convey to the lung an antiseptic vapor which will reach the part undergoing the pathological changes, we should obtain practical results from the local treatment of pulmonary affections.
'The apparatus consists of an air condensor, an air chamber (Hask) for preserving a continuous current of air, a three-mouthed bottle, "Wolf's;" a spray chamber having three mouths; spray tubes; respiratory tube; mouth-piece.

A spray of the solution in the bottle is thrown (by means of compressed air), against the opposite wall with sufficient force to produce a thorough churning with the atmospheric air, a fine vapor, resembling cigar smoke, which escapes through one of the openings in the glass air chamber to the respiratory tube.

During inspiration through the mouth-piece, air enters the middle mouth of the bottle and displaces the vapor of which the bottle is full. During expiration the air in its turn is displaced, passing out of the middle mouth of the bottle, to make room for the vapor which passes from the glass air chamber to the bottle, where it accumulates for the next inhalation.

A vapor produced by means of th $\mathrm{s}$ apparatus condenses slowly, fifty cu. in. of a vaporized solution, containing carbolic acid, borax, glycerine and water, requiring twenty minutes of a temperature of $60^{n} \mathrm{~F}$. to entirely condense.

Ten cases are now reported in this journal with a cessation of symptoms which leads the patients to consider themselves cured. One case of my own far advanced in the second stage of chronic catarrhal pneumonia, after ten inhalations has gained in ten days two and one-half pounds, and to all intents and purposes is making a rapid recovery.

\section{Dr. W. Everetr Smith then exhibited a}

\section{SEMPTE'S ATOMIZING INHAIFR}

which he has been using in connection with Williams' Pneumatic Cabinet. 'This inhaler was devised by Wm. F. Semple, of Mount Vernon, Ohio, in August, I88 $\mathrm{I}$, and consists of a glass receptacle containing an ordinary atomizer. 'The medicament is held in the bottom of the jar and is atomized either by a rubber hand bulb or more effectually by a cylinder of compresserl air. The spray is projected against the top of the jar, the larger particles are condensed to be re-atomized and only the very finest portions of the spray escape through the inhaling tube.

'l'he vapor thus inhaled has been so churned as it were and broken up that it is as fine and impalpable as smoke, and indeed resembles it in appearance. The mouth-piece to the inhaling tube can readily be removed and attached to a thexible rubber tube so that the vapor can be conducted wherever and in whatever direction one pleases. Any fluid that is readily atomized may be employed, the best menstrum being either fluid petrolatum or a 20 per cent. solution of glycerine in water. 'The resulting vapor will resist condensation for from five to fifteen minutes.

'The atomizer was shown to be identical in its principles of construction with the Evans' Inhaler that was exhibited by Dr. Galvin, and when attached to the cylinder of compressed air produced as fine and perfect a vapor as Livans' apparatus. It has, however, these differences in its favor-is simpler in its construction, more easily cleansed and was perfected and in use four years before Dr. Evans set up his claim; yet Dr. Evans calls his atomizer a " new instrument." 
Further than this, Dr. Evans in his article in the New York Medical Journal of March 6, 1886 , makes no mention of and gives no credit either to the Semple Inhaler or to the Globe Inhaler of Beseer.

Dr. Livass' apparatus is faulty in two particulars the inhaling tube is long and is complicated with three glass globes which must be kept thoroughly antiseptic if we are to assign any dangerous activity to the numerous germs of disease. The patient under treatment must moreover inhale and likewise exhale through this one tube, the three glass globes and the Wolff bottle which contains the medication; each patient ought therefore to have an entire atomizer reserved for his own particular use, since it would be practically impossible to cleanse thoroughly all this complicated arrangement after each application.

Dr. Livans claims, however, as an advantage in favor of his apparatus that the vapor will resist condensation for twenty minutes. But is easily dem. onstrated that with any form of atomizer constructed apon these principles, the increase in the resistance to condensation depends directly upon the increase in the specific gravity of the thid atomized and not upon the particular shape of the atomizer.

The very fact, however, that the vapor refuses to condense for so long a period as twenty minutes is an objection rather than an advantage to the method of treatment. Everyone grants that ordinary atomizers are of little benefit in the treatment of lung diseases, because the vapor from them condenses almost entirely upon the mouth and pharynx. At the same time no physician would demand that a patient suffering from pulmonary phthisis should actively inhale a medicated vapor longer than twenty or twenty-five minutes at any one time because of the physical exhaustion that would follow a lunger treatment. If then the vapor that is inhaled resists condensation for so long a period as twenty minutes, 1r. Smith claimed that it is just besinning to be deposited upon the bronchial tubes when the treatment is stopped. He had been better satisfied with the results obtained by a vapor that did not resist condensation for nearly so long a period as that claimed by lor. livans.

At the sane time Dr Sinith claimed it to be a fal. lacy that by the use of either the Semple or the Jivans' Inlialer atomized vapor can be deposited upon lung cells, especially if they are diseased so that they are unable to be reaclily expanded. The vapor when finally churned in these inhalers may be deposited. and very likely is deposited upon the larger bronchial tubes, but we nust remember that bronchial tubes are very different from air vesicles and that the volume of air which we ordinarily breathe-the tidal volume-reaches diroctly only the trachea and large bronchi, but enters the air cells in obedience simply to the law of the diffusion of gases.

Unless, therefore, some of the external pressure of the atmosphere be removed from the chest walls, as it is in the Williams' Cabinet, so that the complemental volume of air can be inhaled involuntarily into even remote air vesicles, the only medication that can effectually reach any decided area of lung cells must be gaseous in form. But however finely you may divide aqueous vapor under ordinary conditions of temperature and atmosplicric pressure, you cannot make it gaseous, for a gas is not condensed except under enormous pressure and at exceedingly low temperatures.

J)r. Smith accordingly, while praising the inhalers that were exlsibited, maintained that to derive their greatest benefit they should be used in conjunction with some form of the Pneumatic Cabinet. He has used the inhaler with the cabinet since last December, and has found the results to be highly satisfactory and encouraging.

Dr. Bownitch said that one of the important objects of any inhaler was to force the substance to be inhaled into the pulmonary structures as much as possible. Whatever the arrangement for inhalation may be, the object to be attained is the pulverization of the substance, and its forcible propulsion into the lungs. The inhaler shown by Dr. Smith is always employed in conjunction with the Pneumatic Cabinet, as an aid to its introduction or propulsion into the deeper parts of the pulmonary recesses.

$D_{R}$. KNIGHT stated that the instrument exhibited by Dr Galvin was capable of producing a finely pulverized fluid, and he had never seen anything so fully answering this demand as the one shown at this meeting.

\section{MEDICAL SOCIETY OF THE DISTRICT OF COLUMBIA. \\ Stated Meating, May' 19, 1886.}

Vich-Prisident, WM. H. TAytor, M.D., IN THE ChatR.

'T. E. MCARDhe, M.D., Secretary.

Dr. BRRMANN presented a bottle full of

POIMPl REMOVED FROM A IATIEN'S NOSE,

where they had been growing for the past seven or eight years. The turbinated bones were atrophied and the septum driven to one side. Some of the tumors were gelatinous, but most of them were of a fibroid character.

DR. Jos. 'I'. Howakd read a paper on

\section{UROGI.AUCIN.}

About 1845 Heller discovered in urine a peculiar substance which he called uroxanthine, which, by further treatment with acid reagents at a high temperature, yielded a blue uroglaucin and a red pigment, urrhodine. 'These coloring matters, he proved, were sinilar to those which had been previously discovered by Braconnot, in the urine, composing a substance which he (Braconnot) called cyano urine, and Virchow and Kleitzinsky showed the identity of urrhodine with indigo red, and uroglaucin with indigo blue. It is the latter, apparently, occurring in the urine of a patient under my care, that it is proposed to speak of now. I say apparently, because the sequel may prove it to be something else; consequently, before detailing the case it may be of interest, if not edifying, to briefly consider the history and sources of "indigo blue," with its relation to the urine generally. Indigo blue was first mentioned by IDioscorides as 